\title{
"Characterization and Green Synthesis of Silver Nanoparticles from Plumeria Leaves Extracts: Study of Their Antibacterial Activity".
}

\author{
Vinay.S.P ${ }^{1}$, Chandrasekhar.N ${ }^{* 1}$ \\ ${ }^{1}$ Research Scholar - Research and Development center, Department of Chemistry, Shridevi Institute of \\ Engineering and Technology, Sira Road, Tumakuru - 572106, Karnataka, India. \\ ${ }^{*}$ Professor, Dean Academics and Supervisor - Research and Development center, Department of Chemistry, \\ Shridevi Institute of Engineering and Technology, Sira Road, Tumakuru - 572106, Karnataka, India. \\ Corresponding Author: Chandrasekhar.N (chandruharshu@gmail.com)
}

\begin{abstract}
In the present work, the stable silver nanoparticles were synthesized by the bioreduction method. Aqueous leaf extracts of the Plumeria plant was used as reducing and as capping agent. The color change in reaction mixture from bright green to dark brown color was observed which indication of the reduction of Silver ions into Silver nanoparticles. The formation of silver nanoparticles (AgNPs) was characterized by UV-vis spectroscopy, FT-IR, SEM and XRD studies. The synthesized AgNPs exhibited good Antibacterial potential against gram positive and gram negative bacteria.
\end{abstract}

Keywords: Plumeria, Silver nanoparticles, UV-vis, XRD, SEM, Anti bacterial activity.

\section{Introduction}

Nanotechnology is a branch of science and engineering involving the synthesis of nanoparticles at the nanoscale, i.e. 1 to $100 \mathrm{~nm}$. Nanoparticles possess high surface to volume ratio due to their small size, which gives very distinctive features to the nanoparticles. The study about nanoscience and nanotechnology provides the well developed application of exceptionally miniature things and be capable of the encroachment of all the fields of scientific research and development like Physics, Chemistry, Materials and Metallurgy engineering, Biology and also in Biotechnology [1,2]. At present, there is an emergent need to develop environmentally benevolent nanoparticles synthesis routes, which can be proceeded by biological method instead of chemical methods. The use of ecologically beneficial materials like plant leaf extracts, bacterial cell extracts, fungi and enzymes for the synthesis of nanoparticles proposes abundant benefits in terms of eco-friendliness and compatibility for a wide range of pharmaceuticals. Accordingly, the researchers in the field of nanoparticles synthesis and assembly have turned to biological systems for inspiration [3]. Currently, the use of green synthesis methods for the production of engineered nanomaterials in both industrial application and the scientific research has achieved a massive amount of interests [4]. Green synthesis method is beneficial over other methods which are implemented for the synthesis of nanoparticles. Green synthesis methods are ecofriendly approach and compatible for pharmaceutical and other biomedical applications, as the toxic chemicals are not used in these methods [5]. While chemical synthetic procedures can lead to the generation of toxic chemical by-products or require high temperatures and/or pressure, biosynthesis of nanoparticles using plant extracts provides a facile and 'green' method of nanoparticle synthesis.[6,7] Silver Particles are of more interest in their colloidal perpetrations because of their distinctive properties, like chemical stability, conductivity, catalytic and antibacterial activities [8]. Silver in different forms and as nanoparticles have been used in medicine for dental materials, wound treatment, coating on stainless steel materials, water purification and in sunscreen lotions [9]. Silver has long been recognized as an antiseptic and anti-biotic since is having an inhibitory effect towards many microorganisms [10]. Many researchers are have used variety of plants for the synthesis of silver nanoparticles. The following plants and their extracts have been used for green synthesis; leaves extract of castor oil (Ricinus Communis), khat (Catha Edulis) and sun flower (Helianthus Annuus)[11], Ocimum sanctum[12], Aspergillus oryzae[13], Crinum asiaticum[14], Azadirachta indica aqueous [15,16], Bamboo [17], Dodonaea viscosa and Capparis deciduas[18], Bryophyllum pinnatum[19] and fruit extract of Andean blackberry [20].

Plumeria is a genus of flowering plants in the family, Apocynaceae. Plumeria is related to the Oleander, Nerium oleander, and both possess an irritant, rather similar to that Euphorbia. The leaves of Plumeria are narrow and corrugated dark-green color. The various species of Plumeria are known to have medicinal properties and have a long history of use by indigenous and tribal people in India. The medicinal 
value of this Plumeria species in the treatment of a large number of human ailments is mentioned in Ayurveda, Charaka Samhita, and Sushrita Samhita [21]. In the present work, the green synthesis of AgNPs is attempted with leaves extracts of Plumeria. The AgNPs obtained are characterized and evaluated for their antibacterial activities.

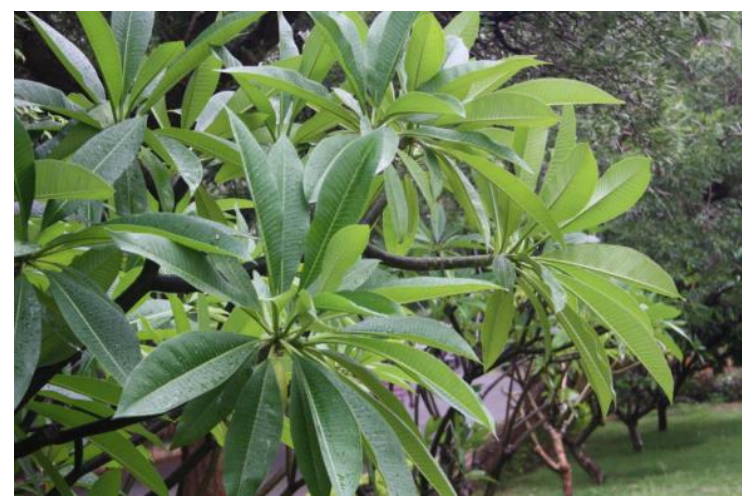

Fig. 1 Plumeria.

\section{A. Materials}

\section{Experimental}

Fresh leaves of Plumeria plant free from diseases were collected from the campus garden of Shridevi Institute of Engineering and Technology, Sira Road, Tumakuru, Karnataka, India. Staphylococus aureus, Klebsiella aerogenes, Pseudomonas aeruginosa and Escherichia coli bacterial strains were collected from department of microbiology, Shridevi Institute of Medical Sciences and Research Hospital, Tumakuru, Karnataka, India.The nutrient media used was supplied by Hi-Media Laboratories. $\mathrm{AgNO}_{3}$ and KCL were procured from Merck, Mumbai, India.

\section{B. Methods}

1) Preparation of leaves extracts:

For the synthesis of silver nanaoparticles, the leaves of Plumeria were washed thoroughly with tap water to remove the dust and dirt particles and then washed with double distilled water. $20 \mathrm{~g}$ of chopped leaves were added to $100 \mathrm{ml}$ double distilled water and stirred at $60^{\circ} \mathrm{c}$ for $30 \mathrm{~min}$ on heating mantle. After boiling, the mixture was cooled for $20 \mathrm{~min}$ and filtered through Whatman filter paper No.1. The collected leaves extracts (bright green color) was used for reducing and as capping agent in AgNPs synthesis.

\section{2) Synthesis of Silver Nanoparticles using Plumeria leaves extracts:}

$5 \mathrm{ml}$ of Plumeria leaves extracts were added to the $45 \mathrm{ml}$ of $5 \mathrm{mM} \mathrm{AgNO}_{3}$ solution at ambient temperature and stirred continuously for $15 \mathrm{~min}$ using magnetic stirrer. Slow reduction takes place and kept for 24 hours to obtain the color change for bio-reduction process. After $24 \mathrm{~h}$ bright green color changed to dark brown color which indicates the formation of AgNPs (Fig.2) The AgNPs obtained from the solution was purified by repeated centrifugation at 8,000 rpm for 15 min using Remi cooling centrifuge C-24. The AgNPs obtained were dried and stored for further analysis.

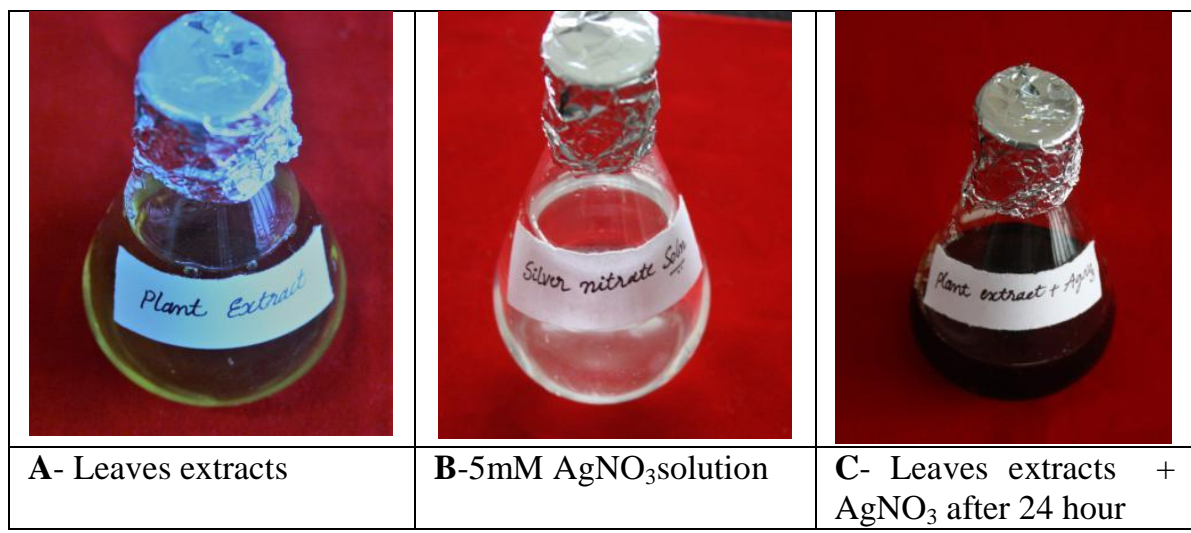

Fig. 2 Formation of AgNPs. 


\section{3) Analysis of Silver nanoparticles:}

a) Phytochemical analysis:

The leaves extracts of Plumeria were assessed for the qualitative determination of chemical constituents i.e. alkaloids, saponins, phenols, flavonoids, tannins, terpenoid and glycosides by applying standard procedures.

\section{b) UV-Vis Spectra analysis:}

The reduction of pure silver ions was observed by measuring the UV-Vis spectrum of the reaction at different time intervals taking $1 \mathrm{ml}$ of the sample, compared with $1 \mathrm{ml}$ of distilled water used as blank.The sample was analysed by UV-Vis spectrophotometry (model Shimadzu UV) for its maximum absorbance v/s wavelength to confirm the formation of AgNPs.

\section{c) Fourier Transform Infra-Red spectroscopy (FT-IR) analysis:}

The sample was mixed with $\mathrm{KCl}$ and a thin sample disc was prepared by pressing with the disc preparing machine and placed in Fourier Transform Infra Red [FTIR] for the analysis of the nanoparticles. The FTIR measurement sample was recorded in the range of $400-4000 \mathrm{~cm}^{-1}$ using Nicolet Avatar model. It gives information on the rotations and vibrations modes were identified and purposed to determined the distinct functional groups present.

d) X-Ray diffraction analysis: The reduced AgNPs powder was coated on a glass substrate and the X-ray diffraction measurement were carried out by using a powder X-ray (PAN analytical BV model) instrument operating at a voltage of $40 \mathrm{kV}$ and current of $30 \mathrm{~mA}$. The output was recorded in the form of a graph with $2 \theta$ on $\mathrm{x}$-axis and then intensity on y-axis. The crystallite average size of particle was calculated by using the DebyeScherrer formula.

$\mathrm{D}=\mathrm{k} \lambda / \beta \cos \theta$,

where $\lambda$ is wavelength, $D$ is particle diameter size, $\beta$ is the full width half maximum, $\mathrm{k}$ is a constant (value 0.9 ) and $\theta$ is Braggs diffraction angle.

\section{e) Scanning Electron Microscopy analysis:}

After the preparation of the nanoparticles, the particle size and their morphological distribution were assessed with Scanning Electron Microscopy (SEM). A drop of aqueous solution containing purified silver nanoparticles obtained after repetitive centrifugation was placed on the carbon coated copper grids and dried under infrared lamp for characterization of their morphology using FEI Quanta 200 Scanning electron microscope at accelerating voltage of $20 \mathrm{keV}$.

\section{f) Antimicrobial activity of silver nanoparticles:}

The antibacterial activity of AgNPs produced by Plumeria leaves extracts were evaluated by the disc diffusion method. Klebsiella aerogenes, Staphylococus aureus, Pseudomonas aeruginosa and E-coli bacterial strains. The bacterial strains were developed in nutrient broth (NB) media for $24 \mathrm{~h}$ at $37^{\circ} \mathrm{c}$ and $1 \mathrm{ml}$ of each broth culture was spread over the nutrient agar media. $5 \mathrm{~mm}$ sterilized filter paper discs were dipped in synthesized Silver nanoparticles suspension $(10 \mu \mathrm{g} / \mathrm{ml})$, double distilled water as negative control, Taxim $(1 \mu \mathrm{g} / \mathrm{ml})$ as standard and leaves extract was placed over the agar plates and incubated for $24 \mathrm{~h}$ at ambient temperature.

\section{a) Phytochemical analysis}

\section{Results And Discussion}

The results of phytochemical analysis of Plumeria leaves extracts are presented in table.1 and flavonoids, saponins, alkaloids, phenols and glycosides are present.

Table.1 Phytochemical analysis of Plumeria leaves extracts

\begin{tabular}{|l|l|c|}
\hline S.No. & Phytochemicals & Leaves extract \\
\hline $\mathbf{1}$ & Flavonoids & ++ \\
\hline $\mathbf{2}$ & Alkaloids & +++ \\
\hline $\mathbf{3}$ & Phenols & ++ \\
\hline $\mathbf{4}$ & Tannins & -- \\
\hline $\mathbf{5}$ & Glycosides & ++ \\
\hline $\mathbf{6}$ & Saponins & +++ \\
\hline $\mathbf{7}$ & Terpenoid & - \\
\hline
\end{tabular}

+: Confirms, - : Absent. 


\section{b) UV-Vis-spectroscopy analysis:}

Reduction of silver ions present in the aqueous solution of silver complex during the reaction with the ingredients present in the Plumeria plant leaves extracts have been studied by the UV-Vis spectroscopy and found that UV-Vis spectrograph of the colloidal solution of AgNPs has been recorded as a function of time by using a quartz cuvette with water as reference. Maximum absorbance peak was observed at $451 \mathrm{~nm}$ indicating that the formation of silver nanoparticles as a result of reduction of $\mathrm{Ag}^{+}$ions present in the aqueous $\mathrm{AgNO}_{3}$ solution (Fig.3).

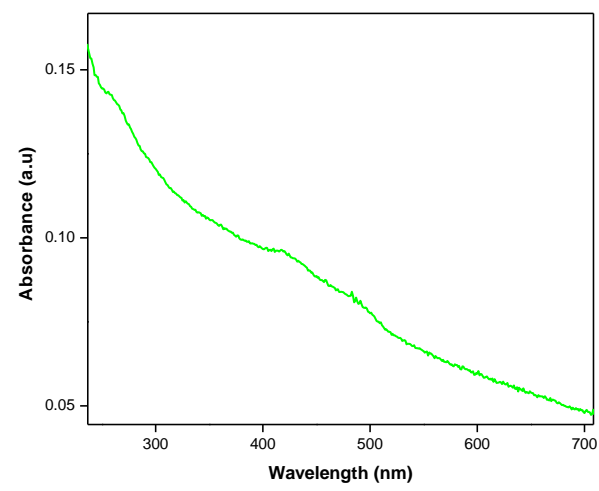

Fig.3 UV-vis spectrum of AgNPs synthesized by Plumeria leaves extract.

\section{c) FT-IR analysis:}

Fourier transform-Infrared (FT-IR) analysis was performed to identify the possible biomolecules responsible for the reduction of the $\mathrm{Ag}^{+}$ions and capping of the reduced AgNPs synthesized using Plumeria leaves extract. The strong IR bonds were observed at 3,703,3381, 2,925, 2333, 1,618, 1,387, 1,070, and 601 $\mathrm{cm}^{-1}$. The bands which appeared at 3,703 and $2,922 \mathrm{~cm}^{-1}$ corresponding to $\mathrm{N}-\mathrm{H},-\mathrm{OH}$ stretching and aliphatic $\mathrm{C}-\mathrm{H}$ stretching, respectively. The bands at 2,333 and $1,618 \mathrm{~cm}^{-1}$ are due to the $\mathrm{CO}_{2}$ and $\mathrm{C}=\mathrm{C}$ stretching, respectively. The IR bands observed at 1,387 and $1,070 \mathrm{~cm}^{-1}$ may be ascribed to $-\mathrm{C}-\mathrm{O}$ and $-\mathrm{C}-0-\mathrm{C}$ stretching modes, respectively. The strong bands recorded at $601 \mathrm{~cm}^{-1}$ in the spectra of the synthesized material were assigned to $\mathrm{C}-\mathrm{H}$ bending peak may be raised due to the reduction of $\mathrm{AgNO}_{3}$ to $\mathrm{Ag}$ nanoparticles (Fig. 4).

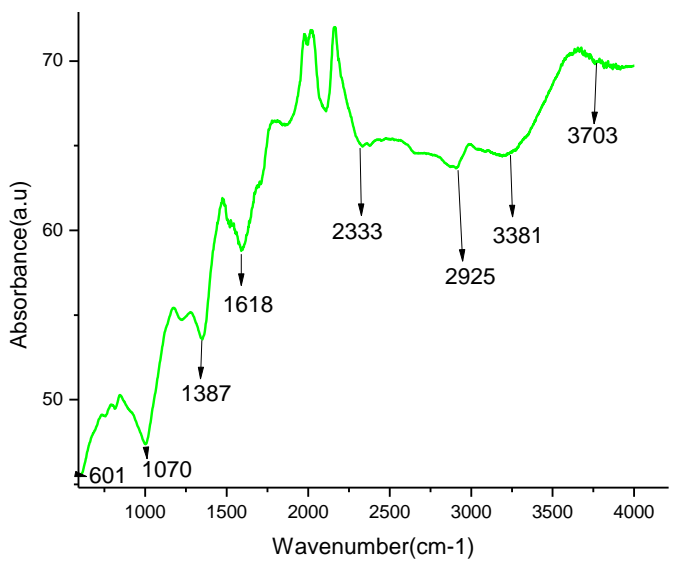

Fig.4 IR spectra of AgNPs synthesized using Plumeria leaves extract.

\section{d) X-ray diffraction:}

X-ray diffraction (XRD) pattern was recorded for the synthesized AgNPs (Fig. 5), shows a number of Bragg reflections corresponding to (111), (200), (220) and (311) sets of lattice planes are observed. Which may be indexed based on the structure of $\mathrm{Ag}$. The diffraction peaks at $2 \theta=38^{\circ}, 44^{\circ}, 64^{\circ}$ and $77^{\circ}$ were indexed with the planes (111), (200), (220) and (311) for the fcc lattice of obtained silver as per the Joint Committee on Powder Diffraction Standards (JCPDS) card no. 04-783 was matched with database. The average size (D) of 
synthesized Silver nanoparticles was found to be $41.7 \mathrm{~nm}$ as calculated by using Debye-Scherer formula. The XRD pattern thus clearly shows that the silver nanoparticles are crystalline in nature.

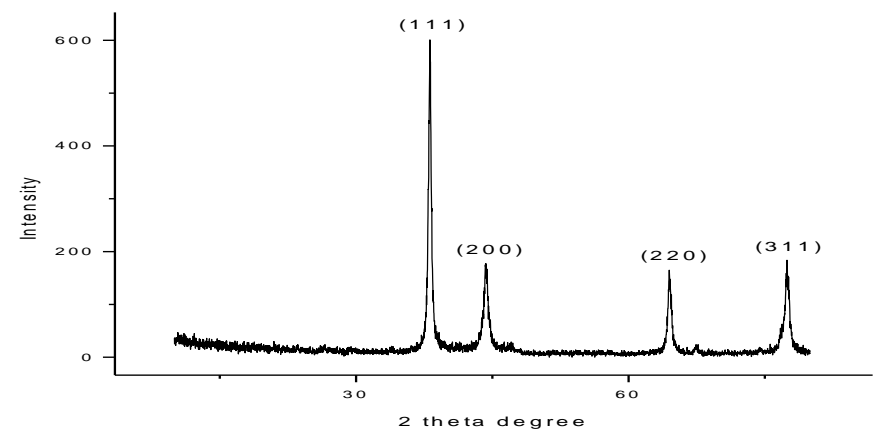

Fig.5 XRD pattern of synthesized AgNPs

\section{e) Scanning Electron Microscopy (SEM) analysis:}

SEM analysis shows the uniformly distributed AgNPs on the surface of the cells. However, it does not indicate that all the NPs are bound to the surface of the cells, because those dispersing in the solution may also deposit onto the surface of the cells. The SEM image (Fig. 6) has shown separate AgNPs as well as particle agglomeration. The SEM study indicates that the particle size is irregular and shape of the particles is spherical in morphology of size ranging from 36 to $47 \mathrm{~nm}$ with an average size of $41.90 \mathrm{~nm}$.

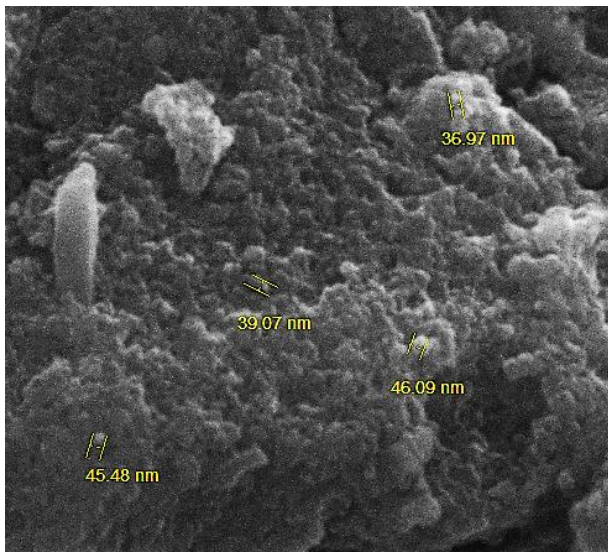

Fig. 6 SEM images of synthesized AgNPs from Plumeria leaves extracts.

\section{f) Antibacterial Assay}

The synthesized AgNPs by the leaves extracts of Plumeria have a significant antibacterial activity against Staphylococus aureus followed by Pseudomonas aeruginosa, Klebsiella aerogenes and E-coli (Fig.7; Table. 2).

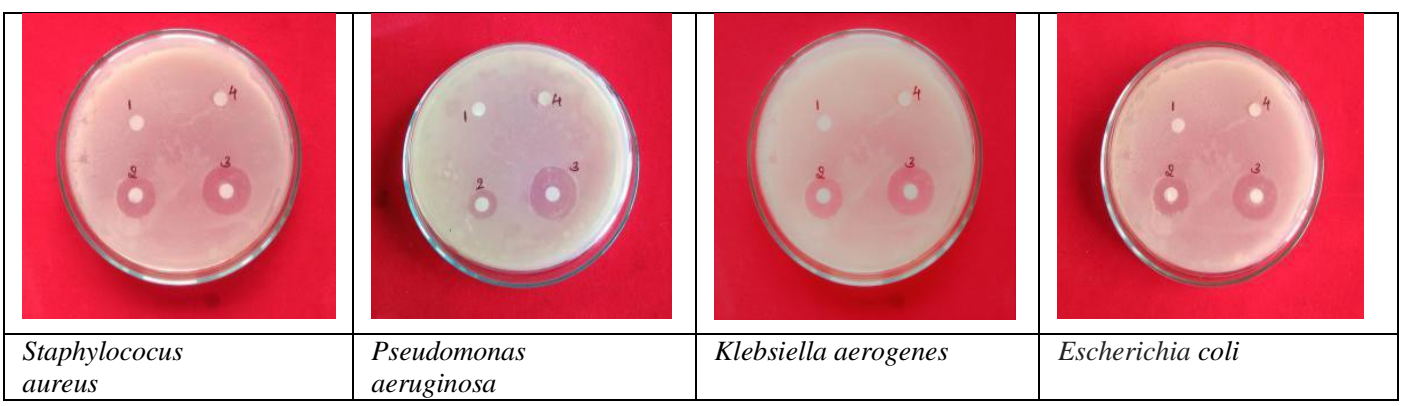

Fig. 7 Antibacterial activity of AgNPs synthesized by leaves extracts of Plumeria

Table.2 Antibacterial Zone of Inhibition.

\begin{tabular}{|c|l|c|c|c|c|}
\hline \multicolumn{5}{|c|}{ Zone of Inhibition (in mm) } & $\begin{array}{r}\text { (4) Leaves } \\
\text { Extract }\end{array}$ \\
\hline S.No & Strains & (1) Control & (2) Standard & $27 \mathrm{~mm}$ & \\
\hline 1 & Escherichia coli & - & $19 \mathrm{~mm}$ & - \\
\hline 2 & Pseudomonas aeruginosa & - & $15 \mathrm{~mm}$ & $27 \mathrm{~mm}$ & - \\
\hline 3 & Klebsiellaaerogenes & - & $18 \mathrm{~mm}$ & $26 \mathrm{~mm}$ & \\
\hline 4 & Staphylococus aureus & - & $19 \mathrm{~mm}$ & $28 \mathrm{~mm}$ & - \\
\hline
\end{tabular}


Control - double distilled water, AgNPs - Silver Nanoparticles, Standard -Taxim, Leaves Extract - Plumeria leaves extracts.

\section{Conclusion}

It is concluded that the leaves extracts of Plumeria is capable of producing silver nanoparticles extracellular and are quite stable in solution. From the XRD data studies the calculated average size of synthesized silver nanoparticles was found to be $41.7 \mathrm{~nm}$. The SEM studies confirm the particle size is irregular and shape of the particles was found to be spherical in morphology with an average size of $41.90 \mathrm{~nm}$. The synthesized AgNPs by Plumeria leaves extracts has shown efficient antimicrobial activities against Escherichia coli, Klebsiella aerogenes, Pseudomonas aeruginosa and Staphylococus aureus.

\section{Acknowledgments}

We thank Dr. M R Hulinaykar, Managing Trustee, Sri Shridevi Charitable Trust, Dr. Gurulingappa M. Patil, Principal, SIET, Tumakuru, India for their encouragement in conducting this research work. We thank the staff, Department of material science, BMSCE, Bangalore, Karnataka, India, for their service in assisting with SEM analysis facility during this research work. We thank the staff, Department of Chemistry, Government Arts and Science College, Bangalore, Karnataka, India, for their service in assisting with FTIR analysis facility during this research work. We thank the staff, Department of microbiology, Shridevi Institute of Medical Sciences and Research Hospital, Tumakuru, Karnataka, India for providing bacterial strains.

\section{References}

[1] Rai, M.,Yadav, A.,Gade,A.Current trends in phytosynthesis of metal nanoparticles. Critical Reviews in Biotechnology 2008; 28(4): pp.277-284

[2] Huang, J., Chen, C., He, N., Hong, J., Lu, Y., Qingbiao, L., Shao, W., Sun, D.,Wang, X. H.,Wang, Y., Yiang, X. Biosynthesis of silver and gold nanoparticles by novel sundried Cinnamomum cam- phora leaf. Nanotechnology 2007; 18: pp.105-106.

[3] Shankar, S. S., Rai, A., Ahmad, A., and Sastry, M. Rapid synthesis of Au, Ag, and bimetallic Au core-Ag shell nanoparticles using Neem (Azadirachtaindica) leaf broth.Journal of Colloid and Interface Science. 2004; 275: pp. 496-502.

[4] DeSimone, J. M. Practical approaches to green solvents.Science 2002; 297: pp.799-803

[5] Willner, B., Basnar, B.Nanoparticle-enzyme hybrid system for nanobiotechnology, FEBS Journal 274 (2007):pp. 302-309.

[6] E. Roduner, Size matters: why nanomaterials are different. Chemical Society Reviews 2006; 35(7): pp.583-592.

[7] M.R Jones et al., Templated Techniques for the Synthesis and Assembly of Plasmonic Nanostructures.,Chemical Reviews, 2011;111(6): pp.3736-3827.

[8] Frattini A, Pellegri N, Nicastro D, De Sanctis O., Effect of amine groups in the synthesis of Ag nanoparticles using aminosilanes. Mat. Chem. Phys. 2005; 94: pp.148-152.

[9] Duran N, Marcato PD, De Souza GI, et al., Antibacterial effect of silver nanoparticles produced by fungal process on textile fabrics and their effluent treatment. J Biomed Nanotechnol. 2007; 3: pp.203-208.

[10] H. Jiang, S. Manolache, A. C. L. Wong, and F. S. Denes., Plasma-enhanced deposition of silver nanoparticles onto polymer and metal surfaces for the generation of antimicrobial characteristics, Journal of Applied Polymer Science. 2004; 93(3): pp.1411-1422.

[11] Hailemariam Gebru, Abi Taddesse, Jyotsna Kaushal and O. P.Yadav. "Green Synthesis of Silver Nanoparticles and their Antibacterial Activity". J. Surface Sci. Technol., 2013; 29(1-2): pp. 47-66.

[12] Yogeswari Rout, Sikha Behera, Akshya Kumar Ojha and P. L. Nayak. "Green synthesis of silver nanoparticles using Ocimum sanctum (Tulashi) and study of their antibacterial and antifungal activities". Journal of Microbiology and Antimicrobials. 2012; 4(6): pp. 103-109.

[13] Probin Phanjom, Giasuddin Ahmed. "Biosynthesis of Silver Nanoparticles by Aspergillus oryzae (MTCC No. 1846) and Its Characterizations". Nanoscience and Nanotechnology 2015; 5(1): pp.14-21.

[14] Malathi. R, Ganesan. V. "Biogenic Synthesis of Silver Nanoparticles using Leaves of Crinum asiaticum Linn”. International Journal of Science and Research, 2014; 3(10): pp. 2238-2243.

[15] Susheela Sharma, Sunil Kumar, B.D. Bulchandini,Shalini Taneja and Shelza Banyal. "Green Synthesis of Silver Nanoparticles and Their Antimicrobial Activity against Gram Positive and Gram Negative Bacteria”. International Journal of Biotechnology and Bioengineering Research. 2013; 4 (4): pp. 341-346.

[16] Shakeel Ahmed, Saifullah, Mudasir Ahmad, Babu Lal Swami, Saiqa Ikram. "Green synthesis of silver nanoparticles using Azadirachta indica aqueous leaf extract”. Journal of Radiation Research and Applied Sciences. 2016; 9: pp. 1-7.

[17] Sohail Yasin , Lin Liu a, Juming Yao. "Biosynthesis of Silver Nanoparticles by Bamboo Leaves Extract and Their Antimicrobial Activity". Journal of Fiber Bioengineering and Informatics. 2013; 6(1): pp. 77-84.

[18] T. Giridharan, Chandran Masi1, S. Sindhu and P. Arumugam. "Studies on Green Synthesis, Characterization and Anti-proliferative Potential of Silver Nano Particle using Dodonaea viscosa and Capparis deciduas". Biosciences Biotechnology Research Asia, 2014; 11(2): pp. 665-673.

[19] Debabrat Baishya, Nakul Sharma and Rituparna Bora. "Green Synthesis of Silver Nanoparticle using Bryophyllum pinnatum (Lam.) and monitoring their antibacterial activities". Archives of Applied Science Research, 2012; 4 (5): pp. 2098-2104.

[20] Brajesh Kumar, Kumari Smita, Luis Cumbal, Alexis Debut. "Green synthesis of silver nanoparticles using Andean blackberry fruit extract". Saudi Journal of Biological Sciences (2015), http://dx.doi.org/10.1016/j.sjbs.2015.09.006.

[21] Shinde P. R., Patil P. S., Bairagi V. A. "Phytopharmacological Review of Plumeria species". Sch. Acad. J. Pharm., 2014; 3(2): pp. 217-227. 


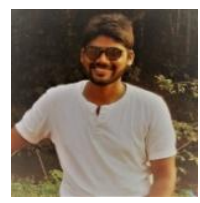

${ }^{1}$ Research Scholar-Research and Development center, Department of Chemistry, Shridevi Institute of Engineering and Technology, Sira Road, Tumakuru - 572106, Karnataka, India.

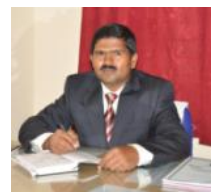

Professor, Dean Academics and Supervisor - Research and Development center, Department of Chemistry, Shridevi Institute of Engineering and Technology, Sira Road, Tumakuru - 572106, Karnataka, India.

IOSR Journal of Applied Chemistry (IOSR-JAC) is UGC approved Journal with Sl. No. 4031, Journal no. 44190.

Vinay.S.P. "“Characterization and Green Synthesis of Silver Nanoparticles from Plumeria Leaves Extracts: Study of Their Antibacterial Activity"." IOSR Journal of Applied Chemistry (IOSR-JAC) 10.7 (2017): 57-63. 